Acta Poetica 25-1

PRIMAVERA

2004

Pura López Colomé

\title{
¿Glosolalia? (Respuesta a Ana Castaño)
}

Quiero comenzar esta pequeña y modesta respuesta a tu ensayo en torno a la glosa con un poema de Enrique Fierro que - cosa que después no te extrañará en lo más mínimo- "se dejó" traducir al inglés (por Alastair Reid) casi tan fluidamente como muchos de los poemas de Borges:

De traducciones y tradicionales confusiones

robaremos hoteles y museos

de formas como colores

colores como ojos

ojos como epidemias

de traducciones y tradicionales

confusiones de formas

como colores

como ojos

como epidemias

de traducciones y tradicionales

confusiones 
Translations and Traditional Confusions

\author{
we will steal from hotels and museums \\ forms like colours \\ colours like eyes \\ eyes like epidemics \\ of translations and traditional \\ confusions of forms \\ like colours \\ like eyes \\ like epidemics \\ of translations and traditional \\ confusions
}

Acostumbrado que está uno a encontrar la pluralidad de sentido, sobre todo en inglés, debido a la flexibilidad de sus usos preposicionales, fácilmente pasaría por alto lo que un simple "de" puede lograr (al irse de la boca, y no por deslenguado o pertenecer al gremio de las malas lenguas, sino por hacerse de la vista gorda). En el original en español, las formas mencionadas en el segundo verso pertenecen a los hoteles y a los museos; el traductor decide robar, extraer no las formas propias de los hoteles, sino sacarlas de su interior, y todo gracias a un from que añade, en vez de la postura más cautelosa y conservadora de una literalidad que, en este caso en particular, por medio de un $o f$, coincidiría con el deliberado of de unos versos más adelante, y que el autor quiso así en su poema. Tenemos, como resultado, un poema transformado. Dado que el traductor es quien es, maestro en estas artes si los hay, nadie pensaría que no entendió el uso original o, menos aún, que lo pasó por alto sin querer. Estamos, entonces, ante un acto de subrepción, "ocultación de un hecho para obtener lo que de otro modo no se conseguiría". ¿Con qué derecho?, preguntarían quienes el propio Alastair llama "the translation police". Con el que asiste al buen entendedor, al verdadero y atento degus- 
tador de las mieles artísticas; al capaz de dar en el clavo de uno de tantos quid pro quo autorizados por la gran diosa, la justicia poética, y crear a un "amado en amada transformado".

Alastair Reid ha sido uno de mis grandes faros en la zona, con frecuencia minada, de la traducción poética. Y he tenido la suerte personal de trabajar a su lado, haciendo confeti de la literalidad mal entendida. Comparada con este sumo traductor de Borges y Neruda, entre tantos otros, yo resulto francamente conservadora, miedosa, frágil. Los riesgos que la vida le ha enseñado a correr son, a estas alturas, francas hazañas. Hace poco me contó que Neruda le decía: "No olvides, querido Alastair, que no quiero que traduzcas mi poesía; quiero que la mejores". Sin envanecerse para nada por esta confianza ciega que sus autores le han conferido, ha ido aprendiendo, a lo largo de ochenta años, que sin desafío - siempre y cuando implique creación, arte, enaltecimiento- la traducción simple y sencillamente carece de sentido. Y esto conlleva, huelga decirlo, una integridad y una moral a prueba de balas (incluso policiacas).

Toda esta larga introducción viene al caso por mi traducción del poema de Seamus Heaney que con tu bien entrenada lupa $\mathrm{y}$ tu impecable gusto literario has tenido a bien tomar en cuenta. Como sabes, el poema original pertenece a una serie en homenaje al poema medieval, escrito en gaélico, titulado Buile Suibhne o, como Heaney lo prefiere, Sweeney Astray (que yo, a mi vez, nombraría quizás El desvarío de Sweeney o La locura de Sweeney o Sweeney desquiciado). El poema en torno al rey-pájaro exiliado a las copas de los árboles por motivo de una maldición inspiró en Heaney, nada menos que su traductor, poemas en reconocimiento a los personajes medievales, cuyo papel, poco reconocido, resultaba esencial en la creación: el escriba, el artista, el clérigo, el ermitaño, el maestro. Y desde luego que $s u$ escriba tiene un poco de todos los otros, así como los otros algo de él. Todos, de alguna manera, encar- 
nan al glosador, quien consagra su vida a la labor del scriptorium haciendo honor a la glosa. El traductor y luego poeta, no conforme con el acto recreativo de su traducción, al dedicarle un poema propio al poema Buile Suibhne no hace otra cosa que despojar a su glosa de cualquier acepción negativa. De haber traducido yo ese primer poema de la serie como "La primera glosa" todo habría sido aceptable y aséptico. ¿Y el famoso desafío? ¿Y la justicia poética? En éstas me hallaba cuando la palabra misma, merced a su otro significado (lustre, brillo), me ofreció una opción con más luz, más connotación y, claro, más riesgo ante la "translation police". Así pues, subrepticiamente, a la Reid, me lancé al vacío. ¿Cuál sería la respuesta de Heaney?: todo un privilegio, de esas ocasiones únicas que lo hacen a uno seguir adelante en tareas tan de suyo ingratas: me envió su ensayo titulado Earning a Rhyme que, cosa curiosa, acababa de publicar en la revista Poetry Ireland, y giraba en torno a su experiencia como traductor de... Buile Suibhne.

Brevemente he de contarte que, en el ensayo, Heaney se pone a sí mismo en tela de juicio. Habla de su primera traducción, demasiado vehemente y apasionada, en la que se permitía añadir, agregar de su cosecha y así enmendar el poema medieval, que le parecía un poco sordo y, en momentos, demasiado seco. Bueno, para ayudarle al lector, Heaney llegaba a llamar Lázaro al monarca, llenándolo de connotaciones ausentes en el original, en su mayoría producto de interpretaciones de un traductor que se sentía con derecho a ir "más allá", con tal de dar a conocer lo magnífico que sí había visto. Muchos años después cayó en la cuenta de que todo lo verdaderamente interpretable se daría a partir de una lectura más sobria, apegada a esa sequedad del primer texto. Las rimas que en un principio le molestaban, y a las que se permitió sustituir por aliteraciones y otras filigranas, probaron ser esenciales para el rescate real: no se había imaginado siquiera la riqueza encerrada en ese quehacer. Tuvo, pues, que hacerse digno de esas 
formas, ganárselas a cabalidad, para ver que eran consustanciales al fondo.

Desde luego que, aprovechando la afortunada posibilidad de dialogar con el autor, incurrí en la obviedad de preguntarle si pensaba que mi "resplandor", en vez de "glosa", no caía precisamente en los terrenos de la vehemencia interpretativa. Para mi consuelo y desahogo, Heaney estuvo de acuerdo contigo, Ana, en que la justicia poética había dado su lugar, su "trono olvidado", a los escribas que arrojaban luz sobre el texto con su glosas, haciéndolas resplandecer. Me daba, de esta manera, dos lecciones: cuidado con la vehemencia, pero arriesga siempre y cuando exista una confirmación por parte de la diosa... que consista en un don de más proporcionado por la lengua anfitriona, algo reconocible como, en palabras de Heaney, un extra bonus. Acaso ese dividendo haya sido un cierto resplandor. 